\title{
WD-repeat protein WDR13 is a novel transcriptional regulator of c-Jun and modulates intestinal homeostasis in mice
}

\author{
Vijay Pratap Singh, Saritha Katta and Satish Kumar
}

\begin{abstract}
Background: WDR13 is a member of the WD repeat protein family and is expressed in several tissues of human and mice. Previous studies in our laboratory showed that the lack of this gene in mice resulted in mild obesity, hyperinsulinemia, enhanced beta cell proliferation and protection from inflammation. However, the molecular mechanism of WDR13 action is not well understood.

Methods: In the present study, we used AOM/DSS to induce colitis-mediated colorectal tumor after establishing expression of Wdr13 gene in colon. Further, we have used human colon cancer cell lines, HT29 and COLO205, and mouse primary embryonic fibroblast to understand the molecular mechanism of WDR13 action.

Results: We observed that mice lacking Wdr13 gene have reduced number of tumors and are more susceptible to DSS-induced colon ulcers. We also show that WDR13 is a part of multi protein complex c-Jun/NCoR1/HDAC3 and it acts as a transcriptional activator of AP1 target genes in the presence of JNK signal. Consistent with in vitro data, we observed reduced expression of AP1 target genes in colon after AOM/DSS treatment in Wdr13 knockout mice as compared to that in wild type.
\end{abstract}

Conclusion: Mice lacking Wdr13 gene showed reduced expression of AP1 target genes and protection from colitis-induced colorectal tumors.

Keywords: JNK signalling, c-Jun, Apoptosis, Colon, Transcriptional activator

\section{Background}

Cell proliferation, cell death and differentiation are basic processes of eukaryotic organisms. These processes are regulated by numerous signals including growth factors, cytokines and extracellular signals, which decide the fate between cell cycle progression and apoptosis through cytoplasmic signalling cascades to the nucleus [1-3]. The Wnt signalling pathway is one of such wellcharacterized signalling pathways, which is believed to be the major pathway controlling intestinal homeostasis and cancer [4] by both canonical and non-canonical routes [5]. Canonical Wnt signalling is mediated by $\beta$ catenin and transcription factor T-cell factor/lymphoidenhancing factor (TCF/LEF) [6]. Non-canonical Wnt

\footnotetext{
* Correspondence: satishk@ccmb.res.in

National Facility for Transgenic and Gene Knockout Mice, CSIR-Centre for Cellular and Molecular Biology, Uppal Road, Habsiguda, Hyderabad 500007, India
}

signalling is activated independent of $\beta$-catenin. The latter is an important pathway mediated through activasignals [1]. As the name indicates, JNK was first identified as a kinase that phosphorylated c-Jun N-terminus [8]. Both canonical and non-canonical Wnt signalling pathways cross talk with each other and target some common genes including $c-M y c$, CyclinD1, Cd44, WNTs, MMPs and $c$-Jun [9].

The proto-oncogene, c-Jun, belongs to the AP1 group cion factors $[10,11]$. c-Jun heterodimerizes families of proteins [12]. AP1 activity, in part, is regulated by phosphorylation of c-Jun at serine residues 63 and 73 and threonine residues 91 and 93 by JNK [13]. c-Jun binds the co-repressor complex NCoR1/ 
HDAC3/TBL1/TBLR1 [14] to repress AP1 target gene transcription. The presence of signal causes recruitment of ubiquitin-conjugating/19S proteasome complex to degrade the repressor complex and recruits the co-activator complex to enhance the expression of AP1 target genes [15]. c-Jun and JNKs are crucial regulators of inflammation, proliferation, apoptosis and cell migration [14, 16, 17] and are involved in malignancy of colon tissues [18].

WDR13 is a member of the WD-repeat protein family, conserved in vertebrates and expressed ubiquitously in many tissues [19-21]. A previous report from our laboratory showed that the absence of WDR13 led to enhanced pancreatic beta cell proliferation in mice [22] and the lack of this protein in a diabetic mouse model (Leptin receptor mutant), which has augmented JNK activity, showed reduced levels of AP1 target genes [23] and protection from inflammation. To understand the role of this protein in cell cycle and regulation of AP1 target genes, we used colitis-induced colorectal mouse model in the present study. We show that the lack of Wdr13 gene protects mice from AOM/DSS-induced colorectal tumors. We also show that WDR13 acts as a transcriptional activator of AP1 target genes in the presence of JNK signal.

\section{Methods}

\section{Animals}

All mice used in this study were maintained in C57BL/ $6 \mathrm{~J}$ genetic background. Mice were housed in normal cages with corncob bedding and a regular light/dark cycle $(6.00$ am to $6.00 \mathrm{pm})$ and were provided with free access to food and water. Mice were euthanized by cervical dislocation. Total 33 mice were used in this study. All animal experiments were approved by the institutional animal ethics committee of CSIR-Centre for Cellular and Molecular Biology, Hyderabad, India.

\section{Cell culture and transfections}

Primary mouse embryonic fibroblasts (MEFs) were isolated from $13.5 d p c$ mouse embryos as described previously [23]. Tails of individual embryos were used to determine genotypes at $\mathrm{Wdr} 13$ locus as described earlier [22]. MEFs were grown in culture media containing $13.3 \mathrm{~g} / \mathrm{L}$ DMEM, $3.7 \mathrm{~g} / \mathrm{L}$ NaHCO3, 10\% serum, 50 g/ $\mathrm{ml}$ ampicillin and $50 \mu \mathrm{g} / \mathrm{ml}$ streptomycin. For analysis of proliferation curve at passage $3,5.0 \times 10^{3}$ cells were seeded in 24 well plates in triplicate and cells were counted at $48 \mathrm{~h}$ intervals. HEK293, MCF7, HT29, COLO205 and MIN6 cells were obtained from the National Centre for Cell Science, Pune, India (purchased from American-Type Culture Collection) and were cultured in complete media as mentioned above for MEFs. The cultures were confirmed negative for mycoplasma.
For transfection of primary MEFs, Lipofectamin-LTX/ Plus reagent (Invitrogen) was used, whereas for other cell lines Lipofectamin 2000 (Invitrogen) was used as per the manufacturer's instructions. In all the reporter assays, cells after transfection were cultured in DMEM media containing $10 \%$ serum for $24 \mathrm{~h}$ and shifted to DMEM media containing 0.5\% serum with treatment for additional time as mentioned in figure legends, except for reporter assay in UV-treated cells. In the latter experiments, cells were cultured in DMEM media containing $10 \%$ serum till the termination of experiment. JNK activity was either activated with anisomycin $(1 \mu \mathrm{M}$-Millipore $)$ or with UV $\left(40 \mathrm{~J} / \mathrm{m}^{2}\right)$ for additional time mentioned in the respective figures. Reporter activity was measured using either dual reporter assay (Promega) or luciferase assay (Promega) with $\beta$-gal.

\section{Expression constructs}

pCMV-FLAG-Wdr13 plasmid was constructed by cloning $W d r 13$ cDNA at EcoRI and XbaI sites of pCMVFLAG plasmid using primer pairs 5'-CCGGAATTCCG GATGGCCGCGGTGTGG-3' and 5'- CCGCTCTAGAT CTAGAGCAGCACAGGGTGAC-3'. FLAG-tagged deletion constructs for WDR13 protein (Fig. 5c) namely; FL-93, FL-193, FL-293, FL-393 were constructed using forward primers

\section{5'-CCCGGAATTCCGGATGGAGGACTTTGAAG-3', 5'-CCCGGAATTCCGGCTGGACGGCAGCATCTC CCT-3, 5'-CCCGGAATTCCGGGGCAAGAAAGTGAAGGG TGG-3', 5'- CCCGGAATTCCGGCTACAGCTGAAGAGAAG CTT-3' respectively and reverse primer 5'-CCGCTCTAGATCTAGAGCAGCACAGGGTGA C-3'.}

pCMV-Myc-Wdr13 plasmid was constructed by cloning $W d r 13$ cDNA at EcoRI and $\mathrm{XbaI}$ sites of pCMV-Myc vector containing Myc peptide sequence at the $\mathrm{N}$ terminal. Myc tagged c-Jun over-expression vector was constructed by cloning c-Jun coding sequences at endfilled EcoRI and XbaI sites of pCMV-Myc using primer pair 5'-CCCGGAATTCCGGATGACTGCAAAGATGG AAAC-3' and 5'- CCGCTCTAGATCTAGATCAAAAC GTTTGCAACTGCT-3'. To obtain the c-Jun deletion constructs (Fig. 5d), forward primers 5'-CATGACTGC AAAGATGGAAAC-3', 5'-CAAGAACGTGACCGACG AGCA-3', 5'-CGCGGTGGCCTCAGTAGCAGG-3' and reverse primers 5'-TCAAAACGTTTGCAACTGCT-3', 5'-TCAGATCCGCTCCTGAGACT-3' were used to amplify the respective constructs and cloned at end-filled $E c o R I$ and $X b a I$ sites of pCMV-Myc. All the FLAG-tagged HDAC vectors were a kind gift from Ronald M. Evans. To 
study the WDR13 protein isoforms, complete $W d r 13$ cDNA was cloned in pCI vector (Promega). All the three predicted initiation codon ATGs (at positions 1, 93 and 123) (Fig. 1c) were mutated to CTG using phusion site directed mutagenesis kit (F541-NEB). The primers used for SDM were the following-

\section{$1^{\text {st }}$ ATG FP- 5'-AGAAGGAAGCCAGGGACTGGCCG CGGTGTGGCA-3' \\ $1^{\text {st }}$ ATG RP- 5'-TGCCACACCGCGGCCAGTCCCTG GCTTCCTTCT-3' \\ $93^{\text {rd }}$ ATG FP- 5' - AACAACCCTTGATCGACTGGAG GACTTTGAAGA-3' \\ 93 ${ }^{\text {rd }}$ ATG RP- 5'-TCTTCAAAGTCCTCCAGTCGAT CAAGGGTTGTT-3' \\ $123^{\text {rd }}$ ATG FP $-5^{\prime}$-CCAGCTGCAGGCACAACTGAA CCGTGCAGTCTA-3' \\ $123^{\text {rd }}$ ATG RP- 5'-TAGACTGCACGGTTCAGTTGT GCCTGCAGCTGG-3'}

PCR reactions were performed using phusion hot start high fidelity DNA polymerase (F540-NEB), and the amplicons were confirmed by DNA sequencing.

\section{RNA isolation, reverse transcription, real time PCR and} western blot analysis

Total RNA was isolated using RNeasy Mini Kit (Qiagen). Reverse transcription was performed using ImPromIITM kit (Promega) after DNase (Promega) treatment of RNA samples. Real time PCR was performed for various genes using Syber Green master mix (Invitrogen) and the list of primers sequences is provided in Additional file 1: Table S1. Western blots were performed after extraction of proteins from various tissues and cell lines in RIPA buffer and blotted on PVDF membrane. Anti-WDR13 purified antibody (HPA000913), FLAG (F3165) from Sigma, p53 (sc-126), c-Jun (sc-45), p-cJun (sc-822), SMRT (sc-1610), actin (sc-47778) from Santacruz, p-JNK (9251), t-JNK (9252), NcoR1 (5948) from Cell Signalling and Myc-HRP (R951-25) from Invitrogen were used for visualization of the respective proteins.

\section{Cell cycle analysis and apoptosis}

MEFs were cultured in complete media till passage 2. At this stage, cells were seeded in $100 \mathrm{~mm}$ dish at a density of $1 \times 10^{6}$ cells per dish. To unsynchronized cells $10 \mu \mathrm{M}$ BrdU was added for $30 \mathrm{~min}$ and cells were collected by trypsinization. Cells were washed with PBS, fixed in 70\% ethanol and stored at $-20{ }^{\circ} \mathrm{C}$. BrdU FITC Set (556028, BD Pharmingen ${ }^{\mathrm{Tx}}$ ) was used to stain BrdU-positive cells. Cells were analyzed using fluorescence activated cell sorter (BD FACS Calibur). Annexin V - FLUOS (1828681-Roche) was used to study the number of apoptotic cells using BD FACS Calibur.

\section{Immunoprecipitation}

For co-immunoprecipitation, DNAs were transfected into HEK293 cells using Xfect reagent. After 48 h, cells were lysed in lysis buffer $(50 \mathrm{mM}-$ Tris. $\mathrm{HCl}, 150 \mathrm{mM}$ $\mathrm{NaCl}, 1$ mM-EDTA, $1 \%$ Triton $\mathrm{X}-100$ and protease inhibitor cocktail). Cell lysate was centrifuged and pre-

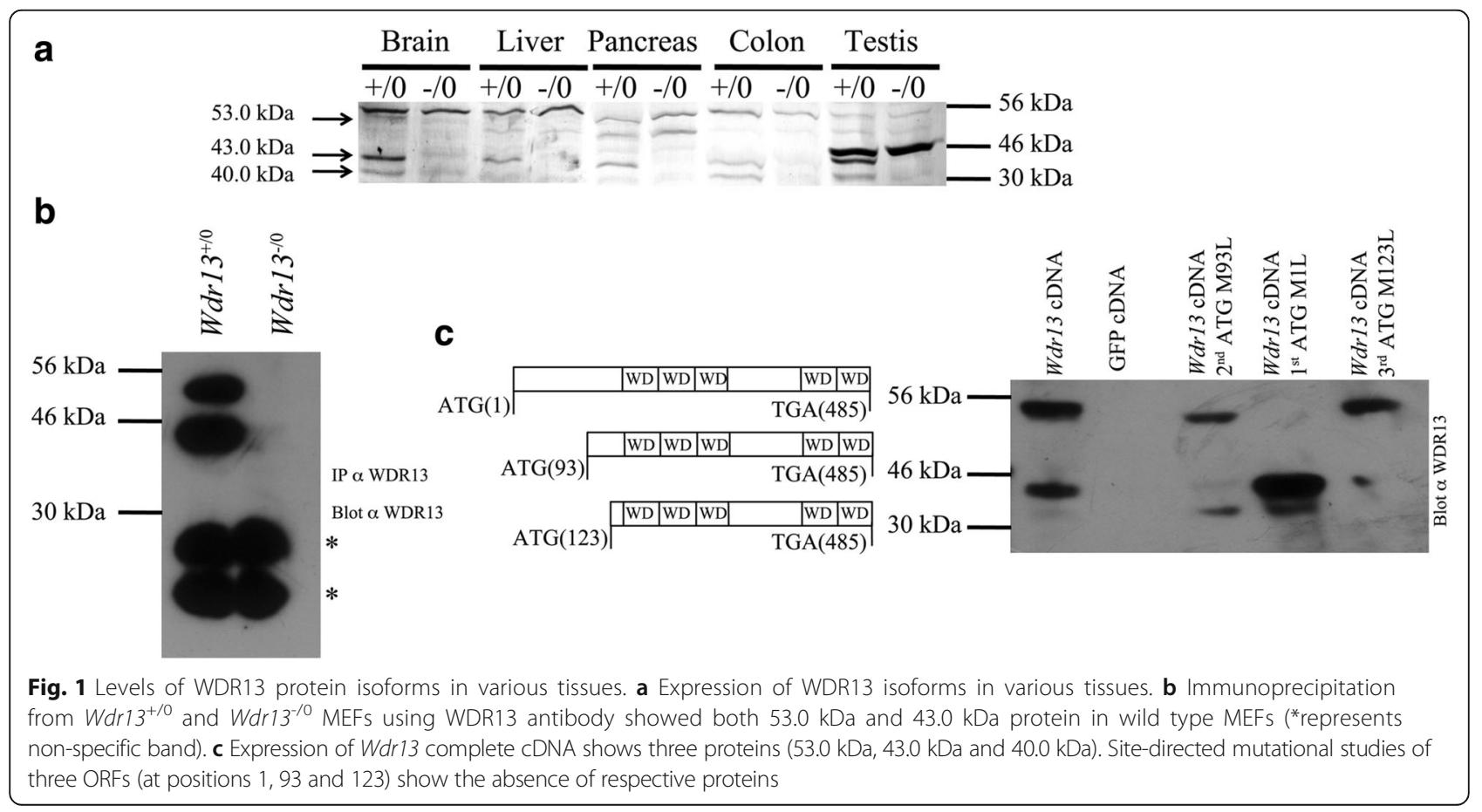


cleaned with Protein G. Anti-FLAG agarose beads (F2220-Sigma) were added to the pre-cleaned lysate and incubated for $4 \mathrm{~h}$ at $4{ }^{\circ} \mathrm{C}$. Immuno complex was washed $4 \mathrm{x}$ with wash buffer $(50 \mathrm{mM}-$ Tris. $\mathrm{HCl}, 150 \mathrm{mM}-\mathrm{NaCl}$, 1 mM-EDTA, $0.5 \%$-Triton X-100 and Protease inhibitor cocktail). The immunocomplex was eluted, separated on 6-10\% SDS PAGE and blotted on PVDF membrane. For endogenous protein-protein interactions, MEFs were collected from T150 for each immunoprecipitation reaction and lysed in lysis buffer as mentioned above. Cell lysates were pre-cleaned with Protein A, and $4 \mu \mathrm{g}$ of $\alpha$ WDR13 antibody was used for immunoprecipitation.

\section{Chromatin immunoprecipitation}

MEFs were grown in complete DMEM media in T150 for each ChIP experiment. The cells were crosslinked in $1 \%$ formaldehyde for $10 \mathrm{~min}$ at room temperature and scraped in PBS containing protease inhibitors. Chromatin immunoprecipitation was performed using chromatin immunoprecipitation (ChIP) Assay Kit (Millipore 7-295) as per the manufacturer's instructions. Briefly, cells were lysed in SDS lysis buffer and sonicated for 42 cycles $(30 \mathrm{~s}$ on/30 s off) using Bioruptor (Diagenode) to get $\sim 200$ 500 bp product size. The cell lysate was pre-cleaned by incubating in agarose beads for $1 \mathrm{~h}$ at room temperature, followed by immunoprecipitation with $3 \mu \mathrm{g}$ anti-WDR13. The beads were washed and the genomic DNA fragments were eluted and purified using phenol/chloroform extraction for real time PCR. To obtain an amplicon spanning the AP1 site, 5'-CATTACCTCAT CCCGTGAGC-3' and 5'- ATCCAGCCTGAGCTCAA CAC-3' primer pair was used.

\section{AOM/DSS model of colon carcinoma}

To induce colon carcinoma, mice were injected intraperitoneally with $10 \mathrm{mg} / \mathrm{kg}$ body weight of AOM (Azoxymethane-Sigma) dissolved in saline [24]. Seven days after AOM injection, 2\% DSS (Dextran sodium sulphate -Sigma) was given in drinking water for the next seven days, followed by normal water until the $21^{\text {st }}$ week. At the $21^{\text {st }}$ week, mice were sacrificed after $1.5 \mathrm{~h}$ of $\mathrm{BrdU}$ injection (100 mg/kg body weight). For macroscopic examinations, colons were opened longitudinally and fixed overnight in buffered $4 \%$ para-formaldehyde. For histological examination, colons were fixed overnight in buffered $4 \%$ para-formaldehyde, rolled, embedded in paraffin and sectioned ( $4 \mu \mathrm{m}$ thickness). Sections were mounted on positively charged slides (Fisher Scientific) and were stained either with $H \& E$ or with anti-BrdU antibodies. Primary antibody was detected with superpicture kit (87-8963- Invitrogen). For apoptosis, TUNEL assay was performed as per the manufacturer's instructions (Promega). For western blot and real time PCR, proximal colon was collected in PBS, snap frozen in liquid nitrogen and stored at $-80^{\circ} \mathrm{C}$.

\section{DSS treatment to induce colon injury}

Two percent DSS was given in drinking water for 7 days to mice at 2 months of age. On day 7, DSS was replaced with normal drinking water, which was continued till the $10^{\text {th }}$ day. On the $10^{\text {th }}$ day mice were sacrificed after $1.5 \mathrm{~h}$ of BrdU injection (100 mg/kg body weight). For histological examination, colons were fixed overnight in buffered $4 \%$ para formaldehyde and processed as mentioned above.

\section{Statistical analysis}

The unpaired two-tailed student's $t$-test was used for statistical analysis. Microsoft Excel software was used for calculation of $P$ values. Data are presented as mean \pm S.E.M.

\section{Results \\ Identification of WDR13 protein isoforms and their differential expression}

Previous results from our laboratory showed that $W d r 13$ mRNA is present in various tissues of human and mouse $[19,20]$, and using $W d r 13$ knockout mice we had earlier analysed the role of this gene in beta cells [22]. However, the role of this protein in other tissues is not known. First, we performed western blot analysis to examine the expression of this protein in various tissues. Various tissues showed the presence of different isoforms of WDR13 protein. The tissues examined such as liver, pancreas, colon and testis had $43.0 \mathrm{kDa}$ and $40 \mathrm{kDa}$ protein isoforms (Fig. 1a). Interestingly, brain tissues showed an additional isoform of $53.0 \mathrm{kDa}$ (Fig. 1a). Since we observed some non-specific bands in western blots using anti WDR13 antibody, we derived primary embryonic fibroblasts from $\mathrm{Wdr} 13^{+/ 0}$ and $\mathrm{Wdr} 13^{-/ 0}$ mouse embryos at $13.5 d p c$ [23] and performed immunoprecipitation to validate the antibody. Consistent with the genotypes of the cells, we found $53.0 \mathrm{kDa}$ and $43.0 \mathrm{kDa}$ protein isoforms from $\mathrm{Wdr} 13^{+/ 0}$ MEFs and these were absent in $\mathrm{Wdr}^{-10} 3^{-10}$ MEFs (Fig. 1b). Wdr13 gene contains three ATGs in the predicted open reading frame at positions 1, 93 and 123. Therefore, to rule out the possibility that smaller isoforms were the cleavage products of the larger protein, we cloned complete $W d r 13$ cDNA in pCI mammalian expression vector (Promega) and mutated all the three ATGs (M) to CTG (L) by site-directed mutagenesis. Wdr13 overexpression of complete cDNA in HEK293 cells showed all the three isoforms (Fig. 1c). However, mutation of the respective ATGs led to the loss of expression of the corresponding isoforms (Fig. 1c). These results confirmed that the different isoforms of WDR13 were not cleavage products of the large isoform but were derived from three different translation initiation codons. 
Absence of $W d r 13$ gene greatly reduces the incidence of colitis-induced colorectal tumor

Since the WDR13 protein isoforms are present in various tissues and it is a negative regulator of beta cell proliferation [22], we observed these knockout mice till one year of age for any tumor progression. We did not observe any spontaneous tumor development until one year of age. Given the presence of this protein in colon, we used AOM/DSS (Mr- 40,000) to induce colorectal tumor in order to know whether the lack of $W d r 13$ gene affected tumor progression. The schematic protocol is given in Fig. 2a. We did not find any significant difference in the body weight till the termination of experiments (21 $1^{\text {st }}$ week after AOM injection). Macroscopic examination of colon from the wild-type mice showed 3-7 tumors in distal and middle colon in all animals as expected. Surprisingly, contrary to our hypothesis, $W d r 13^{-10}$ mice had only 0-2 tumors each in their distal colon (Fig. 2b, c). Histological examination of tumor showed adenocarcinoma (Fig. 2d). It is known that DSS treatment causes ulceration and colitis in colon. To rule out the possibility of resistance to DSS-induced ulceration and colitis in $W d r 13^{-/ 0}$ mice, we analysed colon histology of $W d r 13^{+/ 0}$ and $W d r 13^{-/ O}$ mice during the recovery period (Fig. 2e). Histological examination of colon from $\mathrm{Wdr} 13^{+/ 0}$ and $\mathrm{Wdr} 13^{-10}$ mice showed mucosal ulceration and acute inflammatory infiltration (Fig. 2f). Interestingly, $W d r 13^{-10}$ mice showed more ulceration as compared to $W d r 13^{+/ 0}$ mice, suggesting their enhanced susceptibility to DSS treatment (Fig. 2f).
Wdr $13^{-/ 0}$ mice showed increased apoptosis after AOM/ DSS-induced colitis

To understand the mechanism of protection from colitis-induced colon tumor in $W d r 13^{-10}$ mice, we measured the proliferative and apoptotic index of control, and AOM/DSS-treated $\mathrm{Wdr} 13^{+/ 0}$ and $\mathrm{Wdr} 13^{-/ 0}$ mice. The proliferative index was measured by counting the number of BrdU positive cells per crypt excluding tumors. There were no significant differences in proliferative index between $W d r 13^{+/ O}$ and $W d r 13^{-/ O}$ mice (Fig. 3a). Further, we measured the apoptotic cells per crypt excluding tumors using TUNEL assay. Apoptotic index between the untreated $\mathrm{Wdr} 13^{+/ 0}$ and $\mathrm{Wdr} 13^{-/ 0}$ mice was similar. However, after AOM/DSS-induced colitis, there was a significant increase in the number of apoptotic cells in $W d r 13^{-/ O}$ mice as compared to Wdr $13^{+/ O}$ mice (Fig. 3b). These results suggest that the increased apoptosis may be responsible for the removal of cells mutated by AOM, and thus for lower tumor burden in $W d r 13$ deficient mice.

\section{WDR13 is a transcriptional regulator of c-Jun/AP1 target genes}

To understand the mechanism of WDR13 action, we characterized the growth properties of $\mathrm{Wdr}^{+/ 0}$ and $W d r 13^{-/ O}$ MEFs [23]. During initial passages, cell growth, cell proliferation and apoptosis were similar in $\mathrm{Wdr} 13^{+/ 0}$ and $W d r 13^{-/ 0}$ MEFs (Additional file 2: Figure S1). Previous study in our laboratory showed that the over-expression of $W d r 13$ up-regulated p21 protein levels, whereas $W d r 13$

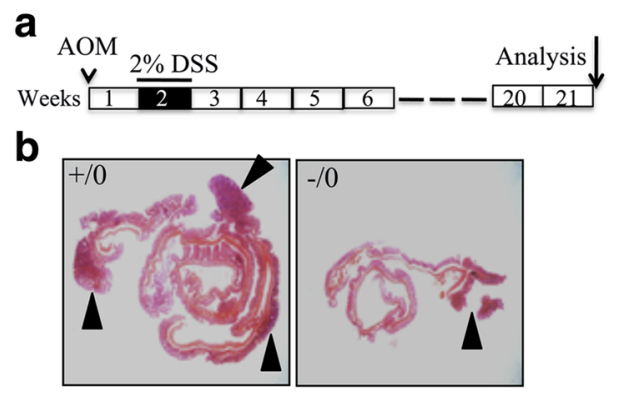

d

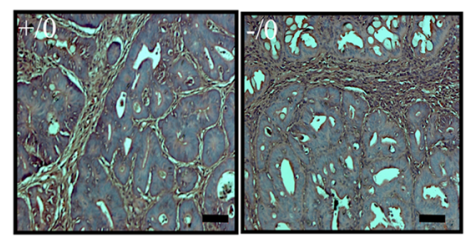

e

C
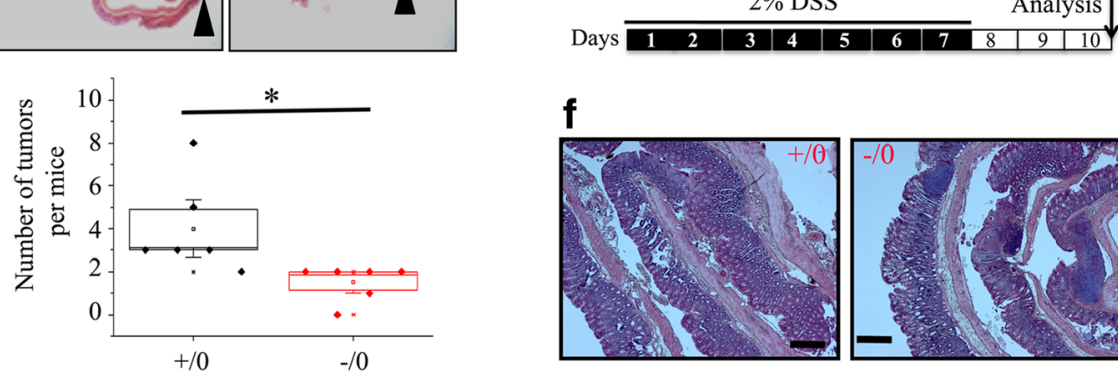

$\mathbf{f}$

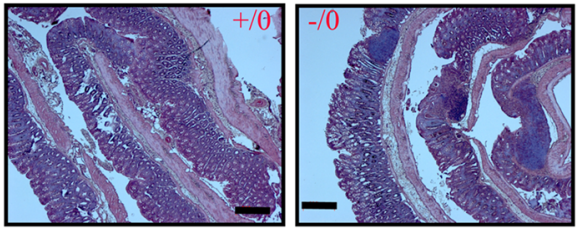

Fig. 2 Wdr13 accelerates colitis-induced colon tumor. a Schematic representation of the experimental design for colitis-induced colon tumor with azoxymethane. $\mathbf{b}$ H\&E staining of colon from Wdr $13^{+/ 0}$ and Wdr $13^{-10}$ mice. c Quantification of number of tumors after AOM/DSS treatment ( $n=$ five $W d r 13^{+/ 0}$ and six $W d r 13^{-/ 0}$ mice). $\mathbf{d}$ H\&E staining of tumor morphology from $W d r 13^{+/ 0}$ and $W d r 13^{-10}$ mice. e Schematic representation of the experimental design for DSS-induced intestinal regeneration ( $n=$ four $W d r 13^{+/ 0}$ and four $W d r 13^{-/ 0}$ mice). $\mathbf{f}$ H\&E staining of colon from Wdr $13^{+/ 0}$ and Wrr $^{-/ 0}$ mice after DSS treatment 

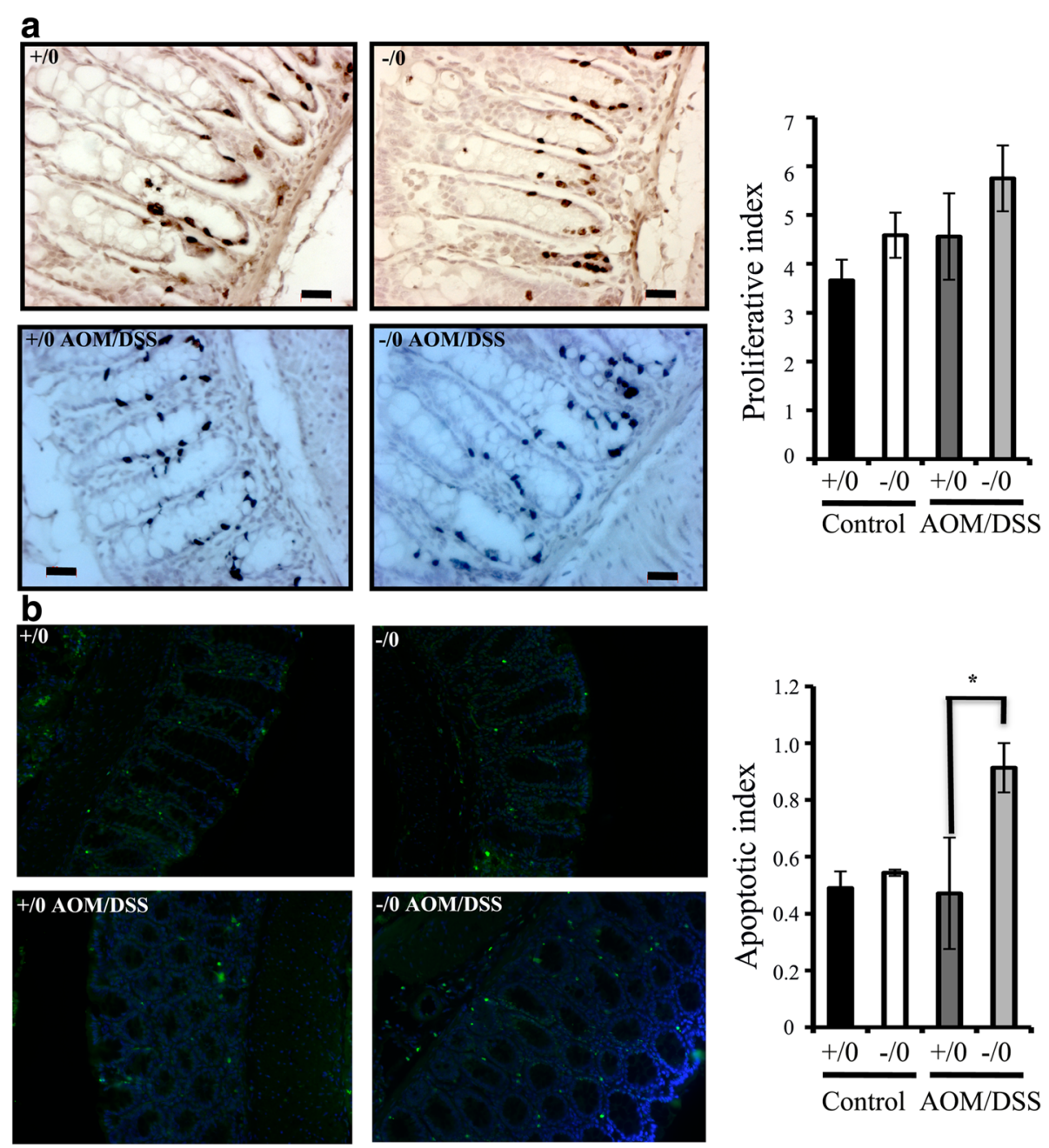

Fig. 3 Cell proliferation and TUNEL analysis of $W d r 13^{+/ 0}$ and $W d r 13^{-10}$ mice colon. a BrdU immunohistochemistry for BrdU positive cells on representative colonic crypts of mice with indicated genotype and treatment. Black bar, Wdr13 $3^{+/ 0}$ mice $(n=34)$; white bar, Wdr13 $3^{-10}$ mice $(n=31)$; Dark grey bar, AOM/DSS-treated Wdr $13^{+/ 0}$ mice $(n=28)$; Light grey bar, AOM/DSS-treated $W d r 13^{-/ 0}$ mice $(n=31)$. $\mathbf{b}$ TUNEL staining for apoptosis on representative colonic crypts of mice with indicated genotype and treatment. Black bar, $W d r 13^{+/ 0}$ mice $(n=132)$; white bar, Wdr $13^{-/ 0}$ mice $(n=162)$; Dark grey bar, AOM/DSS-treated Wdr13 $3^{+/ 0}$ mice $(n=121)$; Light grey bar, AOM/DSS-treated Wdr13 $3^{-/ 0}$ mice $(n=93)$. $\mathrm{n}$ - Shows number of crypts counted for respective genotype. Scale bar, $20 \mu \mathrm{m},{ }^{*}-p<0.05$

knockout mice showed down-regulation of p21 protein levels in pancreatic islets [22]. Consistent with these results, p21 promoter reporter in beta cells (MIN6) showed activation of reporter activity upon WDR13 overexpression (Additional file 3: Figure S2C). p21 protein level is regulated at the transcription and post transcription/post translation levels by various transcription factors, of which p53 and c-Jun are well documented $[25,26]$. Therefore, we analysed the expression of p53 and c-Jun protein levels in $\mathrm{Wdr} 13^{+/ 0}$ and $\mathrm{Wdr} 13^{-10}$ MEFs before and after UV treatment. There was no difference in p53 expression levels between the two genotypes (Fig. 4a). As expected, after UV treatment Wdr $13^{+/ 0}$ MEFs showed increase in c-Jun protein levels with time. However, Wdr13 $3^{-10}$ MEFs did not show any increase in c-Jun protein levels (Fig. 4b). The basal level of c-Jun protein before UV treatment in $\mathrm{Wdr}_{13^{-/ 0}}$ was higher than that in $\mathrm{Wdr} 13^{+/ 0} \mathrm{MEFs}$. The reason of this difference is not clear. c-Jun binds at AP1 sites in the genome and regulates transcription of many genes including its own [13]. The phosphorylation of c-Jun by JNK leads to activation of c-Jun [15, 27], and it is well established that UV-treatment activates JNK pathway by increasing the phosphorylation of JNK [28]. As expected, there was a significant increase in p-JNK levels after UV-treatment in both $\mathrm{Wdr}_{13^{+/ O}}$ and $\mathrm{Wdr}^{-10} \mathrm{MEFs}$ (Fig. 4b).

To further confirm the immunoblot results and to understand the role of WDR13 in c-Jun transcriptional regulation, we used c-Jun reporter containing multiple 


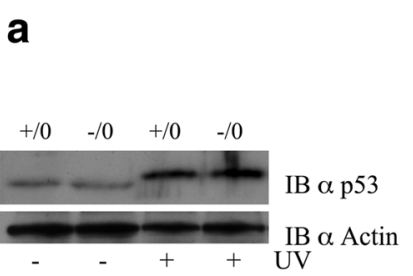

b

b $W d r 13^{+/ 0} \quad W d r 13^{-/ 0}$
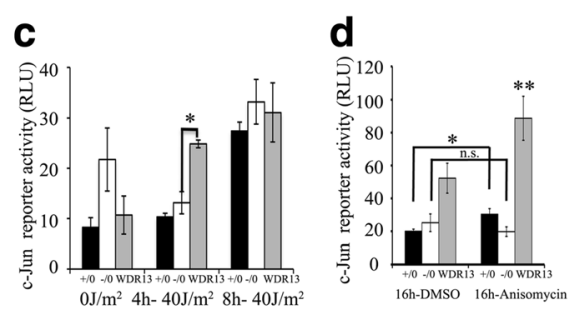
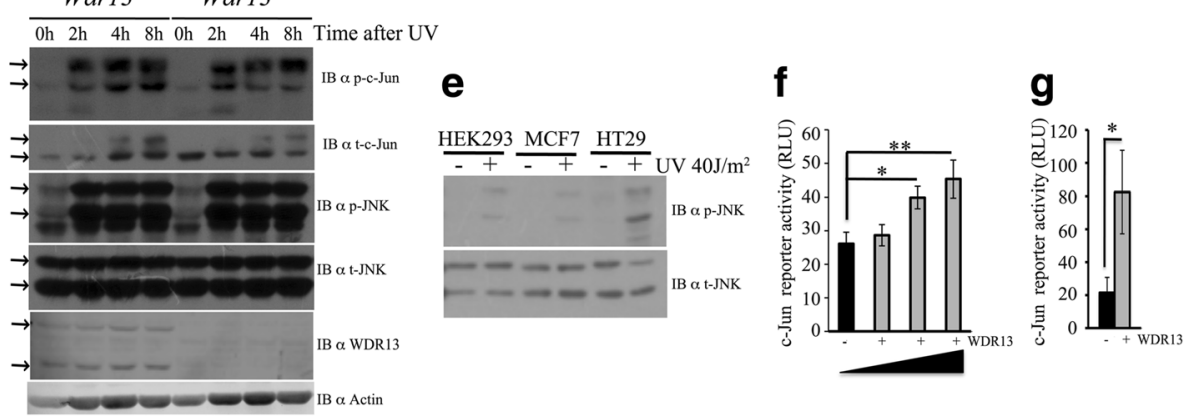

Fig. 4 WDR13 activates c-Jun activity in JNK-dependent manner. a Levels of $\mathrm{p} 53$ in Wdr13 $3^{+/ 0}$ and $W d r 13^{-10} \mathrm{MEF}$ s before and $24 \mathrm{~h}$ after UV treatment $\left(40 \mathrm{~J} / \mathrm{m}^{2}\right)$. Actin was used as loading control. $\mathbf{b}$ Effect of UV on the expression of p-c-Jun, t-c-Jun, p-JNK, t-JNK and WDR13 in Wdr13 $3^{+/ 0}$ and Wdr13 $3^{-10}$ MEFs. Actin was used as loading control. Arrows show specific band. c c-Jun promoter-reporter activity in UV untreated and treated $\left(40 \mathrm{~J} / \mathrm{m}^{2}\right)$ Wdr1 $3^{+/ 0}, W d r 13^{-/ 0}$ and MEFs - over-expressing WDR13 (c-Jun-Luc- $350 \mathrm{ng}$, SV40-RL-100 ng, pGFP-150 ng or pCMV-FLAG-Wdr13-150 ng). d c-Jun promoter-reporter activity in anisomysin untreated and treated $(16 \mathrm{~h}) \mathrm{Wdr} 13^{+/ 0}, \mathrm{Wdr} 13^{-10}$ and MEFs - over-expressing WDR13 (c-Jun-Luc350 ng, $\beta$-gal-100 ng, pGFP-150 ng or pCMV-FLAG-Wdr13-150 ng). For panel C and D, Black bar, Wdr $13^{+/ 0} \mathrm{MEFs}$; white bar, Wdr $13^{-/ 0} \mathrm{MEFs}$; Light grey bar, MEFs over-expressing WDR13; e p-JNK and t-JNK levels in HEK293, MCF7 and HT29 cells before UV treatment and $2 \mathrm{~h}$ after UV treatment. $\mathbf{f} \mathrm{c}-\mathrm{Jun}$ promoter-reporter activity in HT29 cells shows activation of reporter after Wdr13 over-expression in dose-dependent manner (c-Jun-Luc-250 ng, SV40RL-100 ng, pGFP-250 ng, 200 ng, 150 ng, 100 ng, and pCMV-FLAG-Wdr13-0 ng, 50 ng, 100 ng, 150 ng). g c-Jun promoter-reporter activity in COLO205 cells shows activation of reporter after Wdr13 over-expression (c-Jun-Luc-350 ng, SV40-RL-50 ng and pGFP-200 ng or pCMV-FLAG-Wdr13-200 ng). All transfections were performed in technical triplicates. Student's $t$-test was used for statistical analysis and error bar shows S.E.M

(3X) AP1 sites. Consistent with immunoblot results, $8 \mathrm{~h}$ after UV-treatment $\mathrm{Wdr} 13^{+/ 0} \mathrm{MEFs}, \mathrm{Wdr} 13^{-/ 0} \mathrm{MEFs}$ and MEFs over-expressing WDR13 showed 3.3-, 1.5and 3.6-fold induction in the reporter activity (Fig. 4c). Similar to UV-induction, activation of JNK activity by anisomycin also activated c-Jun reporter activity $\approx 1.8$ fold in $\mathrm{Wdr}^{+} \mathrm{3}^{+/ 0}$ MEFs and MEFs over-expressing WDR13. However, $W d r 13^{-/ 0}$ MEFs did not show any activation in reporter activity (Fig. 4d). Consistent with immunoblot results, we also observed increased AP1 reporter activity in $W d r 13^{-/ 0}$ as compared to that in Wdr $13^{+/ O}$ MEFs before JNK activation either by UV or by anisomycin. Next, we performed c-Jun reporter assay in human colon cancer cell line HT29 that has high p-JNK activity (Fig. 4e). Over-expression of Wdr13 gene in HT29 showed a dose-dependent activation of c-Jun reporter (Fig. 4f). Similar results were obtained in another colon cancer cell line, COLO205 (Fig. 4g). Also, activation of JNK activity in MIN6 and HEK293 cells by UV-treatment showed activation of cJun reporter after WDR13 over-expression (Additional file 3: Figure S2B, D). These results suggest that WDR13 activates AP1 target genes in the presence of JNK activity.

\section{WDR13 interacts with c-Jun}

Having established that WDR13 is involved in transcriptional regulation of c-Jun and given that the latter autoregulates its own promoter, we first analysed the interaction of WDR13 with c-Jun. Using anti WDR13 antibody, we purified the immuno-complex from $W d r 13^{+/ 0}$ MEFs. Immuno-blotting of the immunocomplex showed interaction of WDR13 with c-Jun (Fig. 5a). To understand the effect of phosphorylation state of c-Jun on its interaction with WDR13, Myc-cJun and FLAG-Wdr13 were over-expressed in HEK293 cells, and $48 \mathrm{~h}$ after transfection, cells were subjected to UV-treatment to activate JNK. Interestingly, the interaction of WDR13 is enhanced by c-Jun phosphorylation status (Fig. 5b). Domain mapping showed that amino acids 293 to 393 of WDR13 (Fig. 5c, e) and DNA-binding and dimerization domains of c-Jun (Fig. 5d, f) are important for interaction between c-Jun and WDR13. Further, we analysed the interaction of WDR13 with c-Jun promoter using ChIP in MEFs. The results showed occupancy of WDR13 at AP1 site of cJun promoter (Fig. 5g, h). Interestingly, occupancy of WDR13 increases $\approx 4$ fold at AP1 site of c-Jun promoter following JNK activation. 


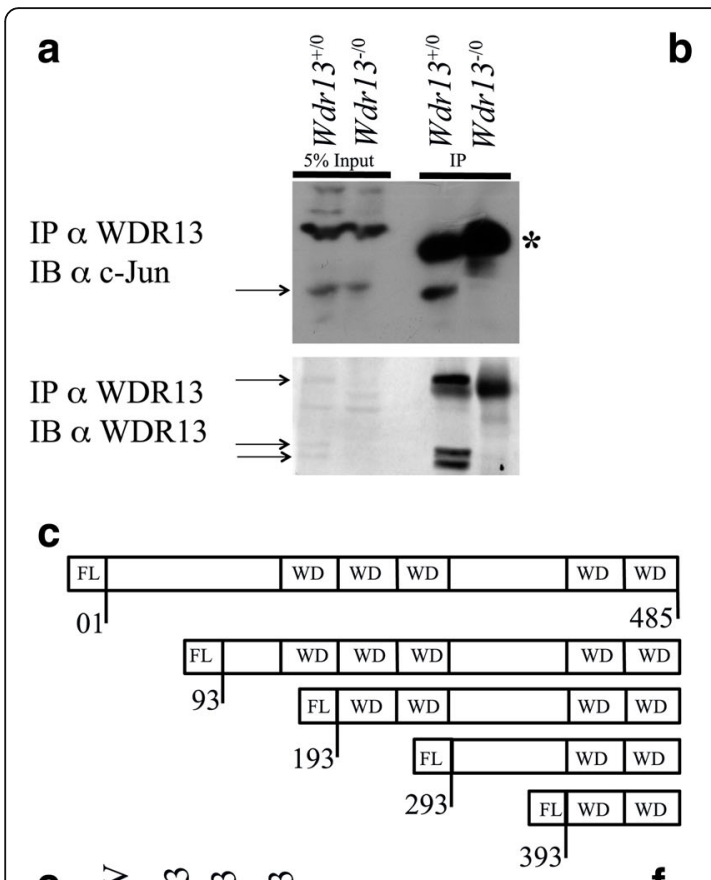

e $\geq m \kappa m$ f

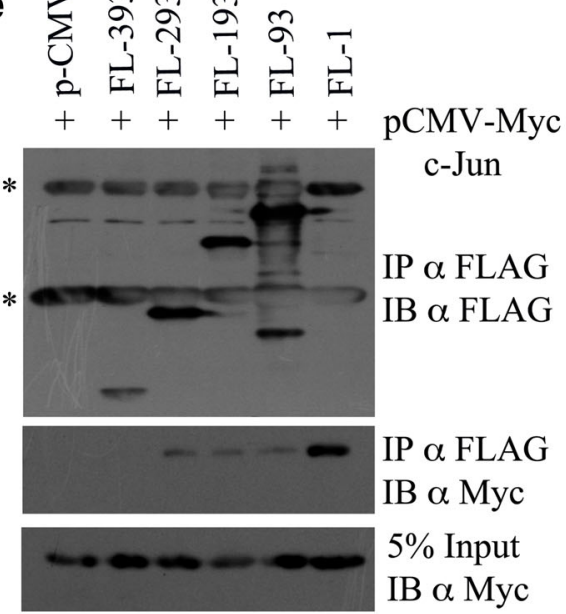

b

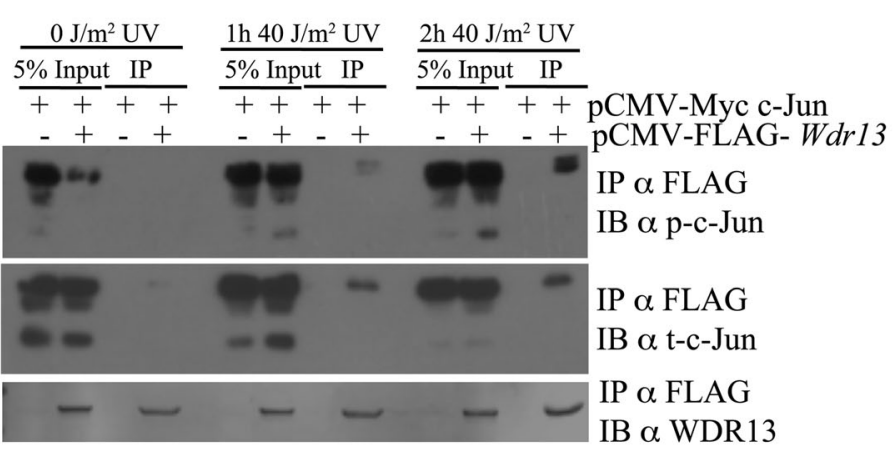

d

WDR13 binding

c-Jun WT (1-334)

c-Jun (1-256)

c-Jun (101-256)

c-Jun (101-334)

c-Jun (145-334)

\section{पMyc $\square$ JNK binding $\square$ DNA binding $\square$ Leucine Zipper}

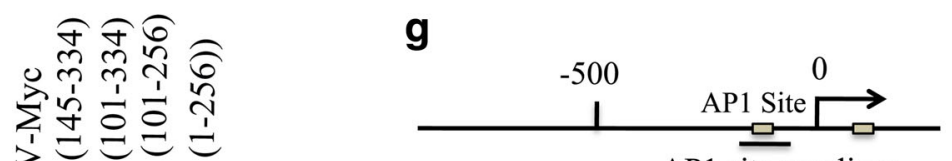

AP1 site amplicon

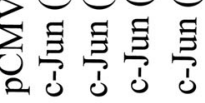

-++++ pCMV-FLAG-Wdr13 h
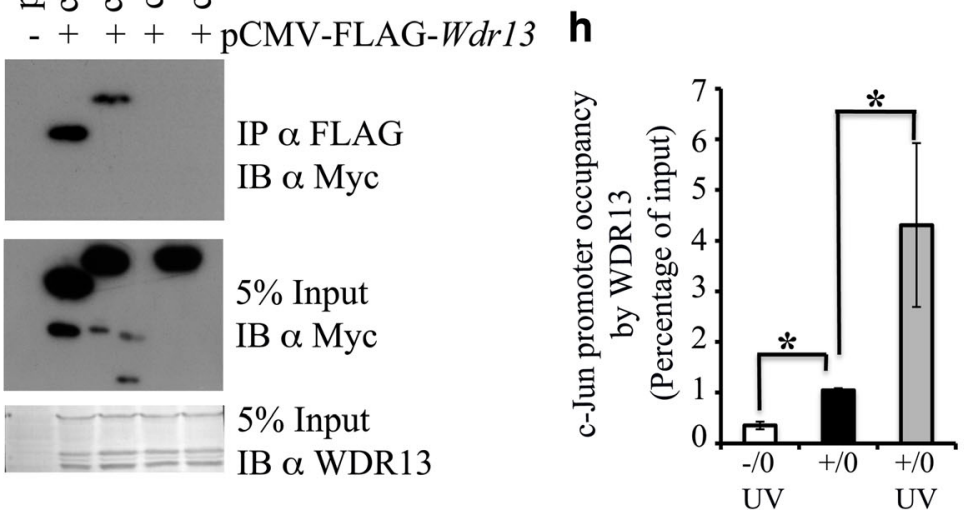

Fig. 5 WDR13 interacts with c-Jun and binds at AP1 sites of c-Jun promoter. a Immunoprecipitation, using anti WDR13 antibody from mouse embryonic fibroblasts shows interaction of WDR13 with c-Jun. Wdr13 knockout MEFs were used as control. Arrows show specific band. * Denotes non-specific band in input and IgG band in IP samples.b Co-immunoprecipitation of Myc-c-Jun and FLAG-WDR13 using anti FLAG agarose beads in HEK293 cells show interaction of WDR13 with c-Jun. Interaction of WDR13 with c-Jun is enhanced as phosphorylation status of c-Jun increases. c Domain organization of WDR13 and schematic of various deletion constructs. $\mathbf{d}$ Domain organization of c-Jun and schematic of various deletion constructs. e Co-immunoprecipitation of Myc-c-Jun and various deleted FLAG-tagged WDR13 domains using anti FLAG agarose beads in HEK293 cells shows that region of 293-393 amino acids is essential for interaction. 5\% input shows protein expression in cell lysate with Myc specific antibody in the lower panels. f Co-immunoprecipitation of FLAG-Wdr13 and various deleted Myc tagged c-Jun domains using anti FLAG agarose beads in HEK293 cells shows interaction of WDR13 with DNAdimerization and DNA-binding domain of c-Jun. 5\% input shows protein expression in cell lysate with WDR13-specific antibody in the lower panels. $\mathbf{g}$ Schematic overview of c-jun promoter. Primer pairs used for ChIP from AP1 site were underlined. $\mathbf{h}$ WDR13 binding to AP1 site of c-Jun promoter in MEFs. Wdr13 knockout MEFs was used as ChIP control. White bar, Wdr13 $3^{-/ 0}$ MEFs $2 \mathrm{~h}$ after UV treatment; black bar, Wdr $13^{+/ 0}$ MEFs; Light grey bar, Wdr1 $13^{+/ 0}$ MEFs $2 \mathrm{~h}$ after UV treatment. ChIP experiment was performed from independently derived two MEFs line for each genotype. Student's t-test was used for statistical analysis and error bar shows S.E.M

WDR13 is a part of c-Jun/NCoR1/HDAC3 complex

Having established that WDR13 is involved in transcriptional regulation and it interacts with c-Jun, we proceeded to identify other possible interacting partners of this protein by purifying the WDR13-containing immunocomplex from HEK293 cells over-expressing FLAG- 
tagged WDR13. Consistent with our above results, we observed that WDR13 interacts with c-Jun (Fig. 6a). In search of co-repressors and co-activators of c-Jun present in the immunocomplex, western blot was performed for various proteins. We observed that WDR13 interacts with NCoR1 but found no evidence of its interaction with SMRT (Fig. 6a). Among the various HDACs analysed, interaction of WDR13 was observed with HDAC1 and HDAC3 (Fig. 6b). We did not find any evidence of interaction of WDR13 with $\beta$-catenin and NFKB (Fig. 6c). Taken together, these data showed that WDR13 regulates AP1 activity by interacting with NCoR1/HDAC3 complex but not with SMRT/HDACs.

\section{WDR13 regulates AP1 target genes in colon}

Since our in-vitro experiments showed that WDR13 regulates AP1 target genes, and as the AOM/DSS-cancer model is known to have higher expression of AP1 target genes, we studied the expression of these genes in colon. First, we analysed the expression of various AP1 target genes that are known to have role(s) in cell proliferation and apoptosis in proximal colon. We observed increased expression of AP1 target genes in the colon of AOM/ DSS-treated control mice (Fig. 7). Interestingly, there was significant reduction in the levels of $\lg r 5$ and $c d 44$ transcripts in $W d r 13^{-/ O}$ mice as compared to those in $W d r 13^{+/ 0}$ mice after AOM/DSS treatment (Fig. 7). These results support the role of WDR13 in regulation of AP1 target genes under JNK activation.

\section{Discussion}

In the present study, we have shown that $W d r 13$ knockout mice were protected to a large extent from AOM/ DSS-induced colorectal tumor. The primary reason for the protection against colitis-induced colorectal tumor in Wdr13 knockout mice is likely to be the resultant ulceration and the increased apoptosis. Experiments designed to co-purify the immune-complex containing WDR13 led to the identification of c-Jun and NCoR1/ HDAC3 complex as interacting partners of WDR13. We have also shown that WDR13 acts as a transcriptional activator of AP1 target genes in the presence of JNK signal.

Repression of c-Jun occurs through various repressor complexes, namely; Mbd3/NuRD [29], Fbl10/Sin3a/ HDACs [30], NCoR1/HDAC3 [14, 27, 31] and SMRT/ HDACs [32]. The existence of many repressors for a single transcription factor such as c-Jun may be required for its tightly controlled regulation in various physiological conditions. Auto regulation of c-Jun further explains the necessity of this tight regulation. From our in-vivo and in-vitro results, it is evident that WDR13 regulates c-Jun transcription and activates AP1 transcription after activation of JNK. Evidence of physical interaction of WDR13 with c-Jun/NCoR1/HDAC3 (Fig. 6a), and the increased WDR13 occupancy at c-Jun promoter after activation of JNKs (Fig. 5h) suggest an important role of this protein in c-Jun transcriptional regulation. The presence of WDR13 in NCoR1/HDAC3 complex and its interaction with c-Jun raise some interesting questions-1) How does WDR13 activate AP1 target genes in the presence of JNK signal? 2) Does this protein have a role in proteosomal degradation of NCoR1/HDAC3 and exchange of co-repressors with coactivators? 3) Does this protein have a role in interaction of JNK and C-Jun? There may be two possibilities; 1 ) WDR13 may be involved in exchange of co-repressors with co-activators in the presence of JNK signal by
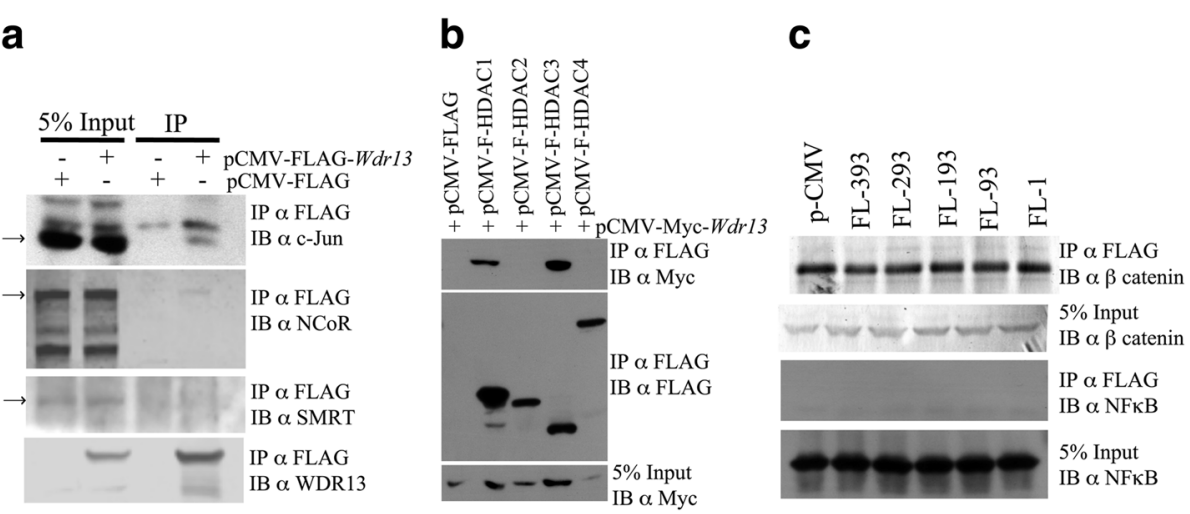

Fig. 6 Interactome of WDR13. a Interaction of FLAG-tagged WDR13 with endogenous NCoR1, SMRT and c-Jun in HEK293 cells. WDR13 interacts with endogenous NCOR1, c-Jun but not with SMRT. Arrows show specific band. b Co-immunoprecipitation of Myc-Wdr13 and various HDACs show interaction of WDR13 with HDAC1 and HDAC3 in HEK293 cells. 5\% input shows protein expression in cell lysate with Myc-specific antibody in the lower panels. $\mathbf{c}$ Interaction of $\beta$-catenin and NFKB with various deletion constructs of FLAG-Wdr13 shows absence of evidence of any interactions in HEK293 cells. Domain organization of WDR13 and schematic of various deletion constructs used in these immunoprecipitation experiments are mentioned in Fig. $5 \mathrm{C}$ 


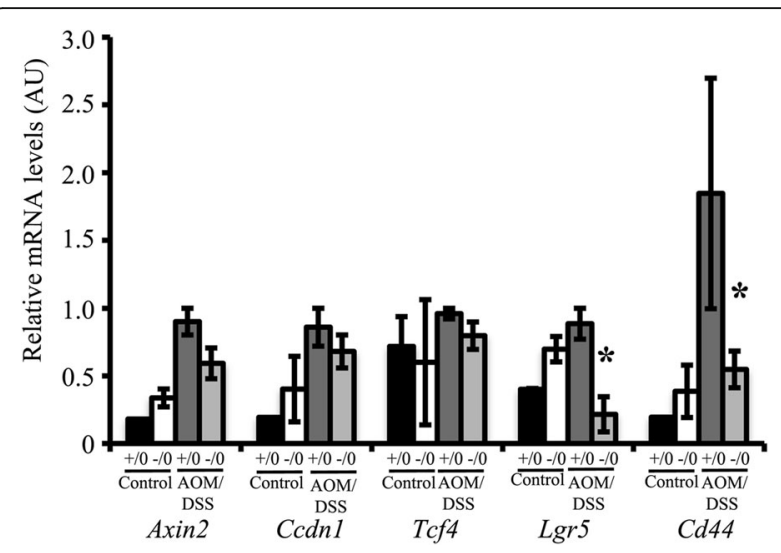

Fig. 7 WDR13 regulates C-Jun function in vivo. Expression analysis of AP1 target genes from proximal colon of indicated genotypes and treatments (excluding tumors). Expression levels were normalized to gapdh. Black bar, Wdr13 $3^{+/ 0}$ mice $(n=2)$; white bar, $W d r 13^{-/ 0}$ mice $(n=2)$; Dark grey bar, AOM/DSS-treated $W d r 13^{+/ 0}$ mice $(n=2)$; Light grey bar, AOM/DSS-treated Wdr $13^{-/ 0}$ mice $(n=3)$. $n$ - Shows number of mice used in respective genotype. All real time PCR was performed in technical triplicate. Student's t-test was used for statistical analysis and error bar shows S.E.M

proteosomal degradation of co-repressors at AP1 sites or 2) WDR13 may act like an adaptor for c-Jun, which in turn helps in both repression and activation of c-Jun in a signal-dependent manner. At present we do not understand which one of the above possibilities exists. However, interaction of c-Jun and JNK is neither dependent upon JNK catalytic activity nor only on the presence of JNK target sites in c-Jun [33]. It has been suggested that JNK in its inactive form contributes to the repressor function [27, 34]. In another study, understanding role of $W d r 13$ gene in the brain tissues, we have observed activation of some of the AP1 target genes in $\mathrm{Wdr} 13^{-/ 0}$ null mice [35] and in present study higher basal AP1 reporter activity in $\mathrm{Wdr} 13^{-/ 0}$ cells and amelioration of AP1 reporter activity after JNK activation suggest that WDR13 is possibly working as c-Jun adapter and may be helping c-Jun/JNK/NCoR1/HDAC3 interactions. However, this needs further validation.

Our previous results in pancreatic beta cells showed that WDR13 binds at p21 promoter and regulates its transcription in MIN6 cells. Since the p21 promoter does not contain an AP1 site, it is possible that binding of WDR13 and c-Jun complex at p21 promoter may be indirectly mediated through sp1 site as suggested by Kardassis et al., [36] or by some other nuclear receptors. In agreement with these results, JNK activation, either by UV in MIN6 and HEK293 cells (Additional file 3: Figure S2C, E) or by anisomycin in MEFs, did not show activation of p21 reporter after WDR13 over-expression (Additional file 3: Figure S2A). These results suggest that regulation of $\mathrm{p} 21$ by WDR13 is not through AP1, but through some other mechanism that may be cell type-specific and is not yet understood. We have provided evidence that WDR13 protein is part of the repressor complex NCoR1/HDAC3. In the presence of JNK signal this protein acts as a transcriptional activator of AP1 target genes. The lack of evidence of interactions of WDR13 with either NFKB and/ or SMRT in our study showed that WDR13 might be exclusively associated with c-Jun and NCoR complex to regulate AP1 target gene transcription.

The role of c-Jun in cell proliferation and malignancy has been shown in many tissues including liver [26], mammary glands [37] and colon [29, 38]. However, the role of c-Jun in apoptosis has been shown to differ in various cell types. Some studies suggest that phosphorylation at serine $63 / 73$ of c-Jun protects cells from apoptosis [39], whereas others suggest that phosphorylation of c-Jun supports apoptosis [40]. WDR13 activates c-Jun activity in JNK-dependent manner, and the lack of WDR13 attenuates c-Jun phosphorylation and its activity. Our results are in agreement with the protective role of c-Jun phosphorylation in apoptosis. The expression of Wdr13 in colon along with the well-known function of c-Jun in the development of colorectal tumor encouraged us to analyze the phenotype of $W d r 13$ knockout mice. There was an increase in expression of AP1 target genes in $\mathrm{Wdr} 13^{+/ 0}$ mice in the proximal colon as compared to control mice after AOM/DSS treatment (Fig. 7). Interestingly, after DSS treatment, $W d r 13^{-/ O}$ mice showed more ulceration (Fig. 2f) than wild-type littermates, which may explain the reduced incidence of colitis-induced colorectal tumor in these mice. Other studies have suggested that the increased apoptosis may lead to increase in ulceration [41]. It is the increased levels of p-JNK in AOM/DSS model that causes induction of AP1 target genes such as $\operatorname{lgr} 5$ and $c d 44$ in $\mathrm{Wdr} 13^{+/ 0}$ mice as compared to nontreated controls [18]. However, there was no activation of AP1 target genes (Fig. 7), and protection from AOM/ DSS-induced colorectal tumor in $\mathrm{Wdr} 13^{-/ 0}$ mice. Various AP1 target genes are regulated by both canonical and non-canonical Wnt signalling due to cross talk among these pathways [9]. In the present study, we did not detect any interaction of WDR13 with $\beta$-catenin (Fig. 6c). These results suggest that the regulation of AP1 target genes by WDR13 is less likely to be through canonical Wnt signalling. However, further experimentation is needed to rule out the involvement of canonical Wnt signalling in the regulation of AP1 target genes in Wdr13 null mice. Some of the AP1 target genes are also regulated by NFKB transcription factor [16], and inactivation of IKK $\beta$ - an activator of $\mathrm{NF}_{\kappa} \mathrm{B}$ in intestinal epithelial cells - leads to dramatic reduction in tumor number after AOM/DSS treatment [41] due to increase in apoptosis. The reduced expression of lgr5 [42] and $c d 44$ [43] in $W d r 13^{-/ 0}$ mice may be another factor responsible for the increase in apoptosis. 
Surprisingly, in spite of the reduced levels of proliferative markers such as $\lg 5$ and $c d 44$ in $W d r 13^{-10}$ mice after AOM/DSS treatment, there was no decrease in the number of BrdU positive cells in crypts of colon. Since inflammation and tumorigenesis are inter-linked, and in this study we used whole body knockout mice, we cannot rule out the involvement of immune cells in reduction of colitis-induced colorectal cancer in these mice. Consistent with these results the reduced inflammation on high fat diet or in diabetic mouse model background in $\mathrm{Wdr} 13^{-/ 0}$ mice may contribute to the increased islet mass and increased beta cell proliferation in pancreas along with the reduced levels of p21 [22, 44].

\section{Conclusions}

In conclusion, we provide evidence that WDR13 is a novel transcriptional activator of AP1 target genes in the presence of JNK signal. The lack of Wdr13 gene conferred protection to a large extent against colitis-induced colorectal tumor in mice through reduced expression of AP1 target genes. Given the expression of WDR13 in various cell types of colon, cell-specific knockout of this gene will further help to explain the phenotype in detail.

\section{Additional files}

Additional file 1: Table S1. Primer list for real time PCR. (DOC $15.5 \mathrm{~kb}$ )

Additional file 2: Figure S1. Cell growth, cell cycle and apoptosis analysis of $W d r 13^{+/ 0}$ and $W d r 13^{-10} \mathrm{MEFs}$ at passage 3. A. Growth curve of $W d r 13^{+/ 0}$ and $W d r 13^{-10}$ MEFs at passage $3(n=3)$. B. Cell cycle analysis of unsynchronized MEFs. C. Annexin V staining of MEFs. $n$ - Shows number of independently derived MEFs used in respective experiments for Wdr $13^{+/ 0}$ and $W d r 13^{-10}$ genotypes. (TIF $4700 \mathrm{~kb}$ )

Additional file 3: Figure S2. Effect of WDR13 on p21 and c-Jun reporter assay in various cell lines. A. p21 promoter activity in MEFs before and after $4 \mathrm{~h}$ treatment of anisomycin. Black bar, Wdr13 $3^{+/ 0} \mathrm{MEFs}$; white bar, Wdr $13^{-/ 0}$ MEFs; Light grey bar, MEFs overexpressing WDR13. (p21-Luc- 350 ng, $\beta$-gal$100 \mathrm{ng}, \mathrm{pGFP}-150 \mathrm{ng}$ or pCMV-FLAG-Wdr13-150 ng) B. c-Jun reporter activity in MIN6 cells $6 \mathrm{~h}$ after UV treatment. C. p21 reporter activity in MIN6 cells before and $6 \mathrm{~h}$ after UV treatment. D. c-Jun reporter activity in HEK293 cells $6 \mathrm{~h}$ after UV treatment. E. p21 reporter activity in HEK293 cells before and $6 \mathrm{~h}$ after UV treatment. (For panel B-E, c-Jun-Luc or p21-Luc- $350 \mathrm{ng}, \beta$-gal$100 \mathrm{ng}, \mathrm{pGFP}-150 \mathrm{ng}$ or pCMV-FLAG-Wdr13-150 ng). All transfections were performed in technical triplicates. (TIF $5959 \mathrm{~kb}$ )

\section{Abbreviations}

AOM: Azoxymethane; AP: Activator protein; CCMB: Centre for cellular and molecular biology; DSS: Dextran sodium sulphate; H\&E: Haematoxylin and eosin; HRP: Horseradish peroxidase; IKKß: Nuclear factor kappa-B kinase subunit beta; JNK: c-Jun N-terminal kinase; LGR5: Leucine-rich repeat-containing G-protein coupled receptor 5; MEF: Mouse embryonic fibroblasts; NFkB: Nuclear factor kappa-light-chain-enhancer of activated B cells;

qRT-PCR: Quantitative RT-PCR; WDR13: WD repeat domain 13

\section{Acknowledgments}

We thank Nandini for microscopy, Srinivas for FACS experiments, Avinash for histology, Sarathi for support in tissue culture, Jyothi for help in animal breeding, and T. Ramakrishna Murti, Chandrashekaran and Archana B. Siva for reviewing the manuscript. We specially thank Prof. Sesikeran for his suggestions and comments on histological sections. We thank Prof. Ronald M. Evans for gifting FLAG-HDAC vectors.

\section{Funding}

This study was partially supported by the Department of Biotechnology, New Delhi by providing VPS a fellowship, and mainly by the Council of -Scientific and Industrial Research, New Delhi. The funder had role in covering the various costs related to this study, including animal maintenance, equipment, reagents and labor.

\section{Availability of data and materials}

All data generated or analysed during this study are included in this published article [and its Additional files] and raw data are available from the corresponding author on reasonable request.

\section{Authors' contributions}

VPS designed experiments, performed experiments and wrote the manuscript. SK performed some of c-Jun reporter assays and Satish Kumar designed experiments and wrote the manuscript. All authors reviewed the results and approved the final version of the manuscript.

\section{Competing interests}

The authors declare that they have no competing interests.

\section{Consent for publication}

Not applicable.

\section{Ethics approval}

The institutional animal ethics committee of CSIR-Centre for Cellular and Molecular Biology, Hyderabad, India approved all the mice experiments.

Received: 26 November 2015 Accepted: 7 February 2017

Published online: 21 February 2017

\section{References}

1. Davis RJ. Signal transduction by the JNK group of MAP kinases. Cell. 2000;103(2):239-52

2. Sherr CJ. G1 phase progression: cycling on cue. Cell. 1994;79(4):551-5.

3. Evan $\mathrm{Gl}$, Vousden $\mathrm{KH}$. Proliferation, cell cycle and apoptosis in cancer. Nature. 2001;411(6835):342-8.

4. Mann B, Gelos M, Siedow A, Hanski ML, Gratchev A, llyas M, Bodmer WF, Moyer MP, Riecken EO, Buhr HJ, et al. Target genes of beta-catenin-T cellfactor/lymphoid-enhancer-factor signaling in human colorectal carcinomas. Proc Natl Acad Sci U S A. 1999;96(4):1603-8.

5. Rao TP, Kuhl M. An updated overview on Wnt signaling pathways: a prelude for more. Circ Res. 2010;106(12):1798-806.

6. Radtke F, Clevers H. Self-renewal and cancer of the gut: two sides of a coin. Science. 2005;307(5717):1904-9.

7. Veeman MT, Axelrod JD, Moon RT. A second canon. Functions and mechanisms of beta-catenin-independent Wnt signaling. Dev Cell. 2003;5(3):367-77.

8. Derijard B, Hibi M, Wu H, Barrett T, Su B, Deng T, Karin M, Davis RJ. JNK1: a protein kinase stimulated by UV light and Ha-Ras that binds and phosphorylates the c-Jun activation domain. Cell. 1994;76(6):1025-37.

9. Saadeddin A, Babaei-Jadidi R, Spencer-Dene B, Nateri AS. The links between transcription, beta-catenin/JNK signaling, and carcinogenesis. Mol Cancer Res. 2009:7(8):1189-96.

10. Shaulian E, Karin M. AP-1 in cell proliferation and survival. Oncogene. 2001; 20(19):2390-400

11. Eferl R, Wagner EF. AP-1: a double-edged sword in tumorigenesis. Nat Rev Cancer. 2003:3(11):859-68.

12. Mechta-Grigoriou F, Gerald D, Yaniv M. The mammalian Jun proteins: redundancy and specificity. Oncogene. 2001;20(19):2378-89.

13. Angel $P$, Hattori $K$, Smeal $T$, Karin M. The jun proto-oncogene is positively autoregulated by its product, Jun/AP-1. Cell. 1988;55(5):875-85.

14. Ogawa S, Lozach J, Jepsen K, Sawka-Verhelle D, Perissi V, Sasik R, Rose DW, Johnson RS, Rosenfeld MG, Glass CK. A nuclear receptor corepressor transcriptional checkpoint controlling activator protein 1-dependent gene networks required for macrophage activation. Proc Natl Acad Sci U S A. 2004;101(40):14461-6.

15. Pulverer BJ, Kyriakis JM, Avruch J, Nikolakaki E, Woodgett JR. Phosphorylation of c-jun mediated by MAP kinases. Nature. 1991; 353(6345):670-4. 
16. Ghisletti S, Huang W, Jepsen K, Benner C, Hardiman G, Rosenfeld MG, Glass CK. Cooperative NCoR/SMRT interactions establish a corepressor-based strategy for integration of inflammatory and anti-inflammatory signaling pathways. Genes Dev. 2009;23(6):681-93.

17. Shaulian E, Karin M. AP-1 as a regulator of cell life and death. Nat Cell Biol. 2002:4(5):E131-6.

18. Sancho R, Nateri AS, de Vinuesa AG, Aguilera C, Nye E, Spencer-Dene B, Behrens A. JNK signalling modulates intestinal homeostasis and tumourigenesis in mice. EMBO J. 2009;28(13):1843-54.

19. Singh BN, Suresh A, UmaPrasad G, Subramanian S, Sultana M, Goel S, Kumar S, Singh L. A highly conserved human gene encoding a novel member of WD-repeat family of proteins (WDR13). Genomics. 2003;81(3):315-28.

20. Suresh A, Shah V, Rani DS, Singh BN, Prasad GU, Subramanian S, Kumar S, Singh $L$. A mouse gene encoding a novel member of the WD family of proteins is highly conserved and predominantly expressed in the testis (Wdr13). Mol Reprod Dev. 2005;72(3):299-310.

21. Singh VP, Alex JL, Lakshmi BJ, Sailasree SP, Raj TA, Kumar S. Role of mouse Wdr13 in placental growth; a genetic evidence for lifetime body weight determination by placenta during development. Sci Rep. 2015;5:13371.

22. Singh VP, Lakshmi BJ, Singh S, Shah V, Goel S, Sarathi DP, Kumar S. Lack of Wdr13 gene in mice leads to enhanced pancreatic beta cell proliferation, hyperinsulinemia and mild obesity. PLoS ONE. 2012;7(6):e38685.

23. Todaro GJ, Green H. Quantitative studies of the growth of mouse embryo cells in culture and their development into established lines. J Cell Biol. 1963;17:299-313.

24. Neufert C, Becker C, Neurath MF. An inducible mouse model of colon carcinogenesis for the analysis of sporadic and inflammation-driven tumor progression. Nat Protoc. 2007;2(8):1998-2004.

25. Schreiber M, Kolbus A, Piu F, Szabowski A, Mohle-Steinlein U, Tian J, Karin M, Angel $P$, Wagner EF. Control of cell cycle progression by c-Jun is p53 dependent. Genes Dev. 1999;13(5):607-19.

26. Stepniak E, Ricci R, Eferl R, Sumara G, Sumara I, Rath M, Hui L, Wagner EF. c-Jun/AP-1 controls liver regeneration by repressing p53/p21 and p38 MAPK activity. Genes Dev. 2006;20(16):2306-14.

27. Weiss C, Schneider S, Wagner EF, Zhang X, Seto E, Bohmann D. JNK phosphorylation relieves HDAC3-dependent suppression of the transcriptional activity of c-Jun. EMBO J. 2003:22(14):3686-95.

28. Shaulian E, Schreiber M, Piu F, Beeche M, Wagner EF, Karin M. The mammalian UV response: $c-J u n$ induction is required for exit from p53-imposed growth arrest. Cell. 2000;103(6):897-907.

29. Aguilera C, Nakagawa K, Sancho R, Chakraborty A, Hendrich B, Behrens A. c-Jun N-terminal phosphorylation antagonises recruitment of the Mbd3/ NuRD repressor complex. Nature. 2011;469(7329):231-5.

30. Koyama-Nasu R, David G, Tanese N. The F-box protein Fbl10 is a novel transcriptional repressor of c-Jun. Nat Cell Biol. 2007;9(9):1074-80.

31. Zhang J, Kalkum M, Chait BT, Roeder RG. The N-CoR-HDAC3 nuclear receptor corepressor complex inhibits the JNK pathway through the integral subunit GPS2. Mol Cell. 2002;9(3):611-23.

32. Lee SK, Kim JH, Lee YC, Cheong J, Lee JW. Silencing mediator of retinoic acid and thyroid hormone receptors, as a novel transcriptional corepressor molecule of activating protein-1, nuclear factor-kappaB, and serum response factor. J Biol Chem. 2000;275(17):12470-4.

33. May GH, Allen KE, Clark W, Funk M, Gillespie DA. Analysis of the interaction between c-Jun and c-Jun N-terminal kinase in vivo. J Biol Chem. 1998; 273(50):33429-35.

34. Dai T, Rubie E, Franklin CC, Kraft A, Gillespie DA, Avruch J, Kyriakis JM, Woodgett JR. Stress-activated protein kinases bind directly to the delta domain of c-Jun in resting cells: implications for repression of c-Jun function. Oncogene. 1995;10(5):849-55.

35. Mitra S, Sameer Kumar GS, Tiwari V, Lakshmi BJ, Thakur SS, Kumar S. Implication of genetic deletion of Wdr13 in mice: mild anxiety, better performance in spatial memory task, with upregulation of multiple synaptic proteins. Front Mol Neurosci. 2016;9:73.

36. Kardassis D, Papakosta P, Pardali K, Moustakas A. c-Jun transactivates the promoter of the human p21(WAF1/Cip1) gene by acting as a superactivator of the ubiquitous transcription factor Sp1. J Biol Chem. 1999;274(41):29572-81.

37. Jiao X, Katiyar S, Willmarth NE, Liu M, Ma X, Flomenberg N, Lisanti MP, Pestell RG. c-Jun induces mammary epithelial cellular invasion and breast cancer stem cell expansion. J Biol Chem. 2010;285(11):8218-26.
38. Nateri AS, Spencer-Dene B, Behrens A. Interaction of phosphorylated c-Jun with TCF4 regulates intestinal cancer development. Nature. 2005;437(7056):281-5

39. Wisdom R, Johnson RS, Moore C. c-Jun regulates cell cycle progression and apoptosis by distinct mechanisms. EMBO J. 1999;18(1):188-97.

40. Behrens A, Sibilia M, Wagner EF. Amino-terminal phosphorylation of c-Jun regulates stress-induced apoptosis and cellular proliferation. Nat Genet. 1999;21(3):326-9.

41. Greten FR, Eckmann L, Greten TF, Park JM, Li ZW, Egan LJ, Kagnoff MF, Karin M. IKKbeta links inflammation and tumorigenesis in a mouse model of colitis-associated cancer. Cell. 2004;118(3):285-96.

42. Saigusa S, Inoue Y, Tanaka K, Toiyama Y, Matsushita K, Kawamura M, Okugawa Y, Hiro J, Uchida K, Mohri Y, et al. Clinical significance of LGR5 and CD44 expression in locally advanced rectal cancer after preoperative chemoradiotherapy. Int J Oncol. 2012;41(5):1643-52.

43. Lakshman M, Subramaniam V, Wong S, Jothy S. CD44 promotes resistance to apoptosis in murine colonic epithelium. J Cell Physiol. 2005;203(3):583-8.

44. Singh VP, Gurunathan C, Singh S, Singh B, Lakshmi BJ, Mishra AP, Kumar S. Genetic deletion of Wdr13 improves the metabolic phenotype of Lepr ( $d b / d b)$ mice by modulating AP1 and PPARgamma target genes. Diabetologia. 2015;58(2):384-92.

\section{Submit your next manuscript to BioMed Central and we will help you at every step:}

- We accept pre-submission inquiries

- Our selector tool helps you to find the most relevant journal

- We provide round the clock customer support

- Convenient online submission

- Thorough peer review

- Inclusion in PubMed and all major indexing services

- Maximum visibility for your research

Submit your manuscript at www.biomedcentral.com/submit
Biomed Central 